\title{
Symbiosis Instead of Competing Demands: A Tale of 2 Preventive Services
}

Ann Fam Med 2011;9:iii. doi.10.1370/afm.1214.

$\mathrm{T}$ The Annals of Family Medicine encourages readers to develop a learning community of those seeking to improve health care and health through enhanced primary care. You can participate by conducting a RADICAL journal club and sharing the results of your discussions in the Annals online discussion for the featured articles. RADICAL is an acronym for Read, Ask, Discuss, Inquire, Collaborate, Act, and Learn. The word radical also indicates the need to engage diverse participants in thinking critically about important issues affecting primary care and then acting on those discussions. ${ }^{1}$

\section{HOW IT WORKS}

In each issue, the Annals selects an article or articles and provides discussion tips and questions. We encourage you to take a RADICAL approach to these materials, and to post a summary of your conversation in our online discussion. (Open the article online and click on "TRACK Comments: Submit a response.") You can find discussion questions and more information online ing at: http://www.AnnFamMed.org/AJC/.

\section{CURRENT SELECTION}

\section{Article for Discussion}

Ruffin MT IV, Nease DE Jr, Sen A, et al. Effect of preventive messages tailored to family history on health behaviors: the Family Healthware Impact Trial. Ann Fam Med. 2011;9(1):3-11.

\section{Discussion Tips}

This cluster-randomized clinical trial assesses the effect of an automated family medical history assessment and tailored messages on preventive behaviors compared with a standard preventive message. In addition to critiquing the study, consider its larger implications for the family focus of family practice and the emerging genetic revolution.

\section{Discussion Questions}

What question is addressed by the article? How does the question fit with what already is known on this topic?

- How does a conceptual model inform the intervention design and your interpretation of the results?
- How strong is the study design for answering the question?

- How do the study methods compare with the CONSORT criteria for clinical trials? ${ }^{2}$

- What is the degree to which can the findings be accounted for by:

1. The choice of the comparison intervention?

2. How participants (settings, practices, clinicians, and patients) were selected? The exclusion criteria and dropouts? Are any biases likely to be important?

3. How outcomes were measured?

4. Confounding (false attribution of causality because 2 variables discovered to be associated actually are associated with a 3 rd factor)?

5 . How information was interpreted?

6. Chance?

- What are the main findings? How large is the effect across different outcomes?

- How transportable are the findings to your clinical setting? What factors might affect this transportability?

- Could you apply these findings to your practice using MyFamilyHealth Portrait, at https://familyhistory.hhs.gov/fhh-web/home.action?

- What are the implications of the current limited utility of most electronic health records (EHRs) for gathering, synthesizing, analyzing and using family history information? Is the growing use of EHRs affecting the family focus of family practice? What is the potential for EHRs to support a family focus to care? How might this potential be realized? How could EHRs support primary care clinicians, patients, and families in managing the forthcoming onslaught of genetic/genomic information?

- What are some next steps for applying the findings or answering other questions that this study raises?

\section{References}

1. Stange KC, Miller WL, McLellan LA, et al. Annals Journal Club: It's time to get RADICAL. Ann Fam Med. 2006;4(3):196-197. http:// annfammed.org/cgi/content/full/4/3/196.

2. CONSORT Group. CONSORT: Consolidated Standards of Reporting Trials. http://www.consort-statement.org/. Accessed Dec 23, 2010. 